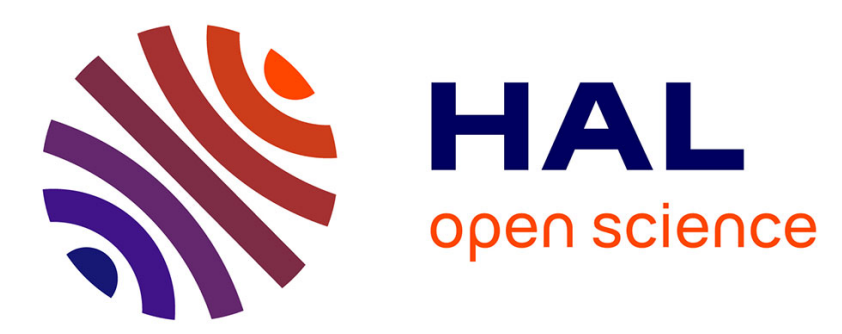

\title{
Impacts of the economic crisis on household transport expenditure and public transport policy: Evidence from the Spanish case
}

\author{
Rocío Cascajo, Lourdes Diaz Olvera, Andrés Monzon, Didier Plat, \\ Jean-Baptiste Ray
}

\section{To cite this version:}

Rocío Cascajo, Lourdes Diaz Olvera, Andrés Monzon, Didier Plat, Jean-Baptiste Ray. Impacts of the economic crisis on household transport expenditure and public transport policy: Evidence from the Spanish case. Transport Policy, 2018, 65, pp.40-50. 10.1016/j.tranpol.2017.06.001 . halshs-01672812

\section{HAL Id: halshs-01672812 \\ https://shs.hal.science/halshs-01672812}

Submitted on 5 Jan 2018

HAL is a multi-disciplinary open access archive for the deposit and dissemination of scientific research documents, whether they are published or not. The documents may come from teaching and research institutions in France or abroad, or from public or private research centers.
L'archive ouverte pluridisciplinaire HAL, est destinée au dépôt et à la diffusion de documents scientifiques de niveau recherche, publiés ou non, émanant des établissements d'enseignement et de recherche français ou étrangers, des laboratoires publics ou privés. 


\title{
Impacts of the economic crisis on household transport expenditure and public transport policy: Evidence of the Spanish case
}

\author{
Rocío Cascajo $^{1}$, Lourdes Diaz Olvera ${ }^{2 *}$, Andrés Monzon ${ }^{3}$, Didier Plat ${ }^{4}$, Jean-Baptiste Ray $^{5}$ \\ ${ }^{1}$ TRANSyT, Universidad Politécnica de Madrid, ETSI Caminos, Canales y Puertos, c/Prof. Aranguren \\ $\mathrm{s} / \mathrm{n}$, \\ 28040 Madrid, Spain, rocio.cascajo@upm.es, +34 913365259 \\ ${ }^{2}$ LAET-Université de Lyon, ENTPE, rue Maurice Audin, 69518 Vaulx en Velin Cedex, France, \\ lourdes.diaz-olvera@entpe.fr, +33 472047244 \\ ${ }^{3}$ TRANSyT, Universidad Politécnica de Madrid, ETSI Caminos, Canales y Puertos, c/Prof. Aranguren \\ $\mathrm{s} / \mathrm{n}$, \\ 28040 Madrid, Spain, andres.monzon@upm.es, +34 913365373 \\ ${ }^{4}$ LAET-Université de Lyon, ENTPE, rue Maurice Audin, 69518 Vaulx en Velin Cedex, France, \\ didier.plat@entpe.fr, +33 472047047 \\ ${ }^{5}$ Arcadis/Movi' cité, 127 Blvd Stalingrad, 69626 Villeurbanne Cedex, France, \\ jeanbaptiste.ray@arcadis.com, \\ +33666111517 \\ * Corresponding author
}

\begin{abstract}
The objective of this paper is to assess the impacts of the economic crisis in Spain on the transport expenditure of households from 2006 to 2014 and how transport authorities reacted to cope with the decreasing public resources and transport demand. The approach is based on quantitative and qualitative sources of information: the Spanish Household Budget Survey and in-depth interviews with public transport policy makers from six metropolitan areas.

Transport is one of the household expenditure items that is the most affected by the crisis. The average amount spent on transport fell to its lowest value in 2013, dropping by $37 \%$ in six years. The proportion of budget spent on transport was reduced by a majority of households, whatever the residential location or purchasing power, with the exception of the poorest. Households reacted promptly to the crisis by reducing their purchases of new cars; their spending on transport use was affected less significantly. Poor households or those living in low-density areas were least able to reduce their transport costs.

To cope with the crisis, public transport authorities reduced transport supply and increased fares. They also implemented other measures to bring in extra income which had no impact on transport services. The research concludes that sustainability-oriented transport policies promoting public transport and the reduction of car dependency, together with sustainable landuse policies, may help to limit the household transport budget and the impacts of an economic crisis on mobility.
\end{abstract}


Keywords: economic crisis; household transport expenditure; household inequalities; urban public transport provision; public transport policy measures; Spain

\section{Highlights}

1. Household expenditure on transport fell from $15.9 \%$ of total expenditure to $13.2 \%$.

2. Only the poorest households increased their share of budget on transport.

3. The purchase of new cars decreased notably from the very beginning of the crisis.

4. Public transport authorities tried to reduce costs and increase revenues.

5. Adaptation to the crisis was easier for the wealthiest households and PT networks. 


\section{Introduction}

The economic and financial crisis that emerged in 2007 has engulfed almost every country and is stronger in intensity and wider in coverage than the Great Depression of the 1930's (Dhameja, 2010; Terazi and Senel, 2011; OECD, 2014). It has affected European countries since 20072008 to different degrees. In the European Union, in 2009, the worst year of the crisis, GDP fell by $4.6 \%$ while household consumption dropped by $1.8 \%$. Government expenditure probably counterbalanced a more significant reduction as it remained almost stable (Gerstberger and Yaneva, 2013). According to the OECD (2014) market income inequality, measured by the Gini coefficient, rose at least one percentage point in 20 OECD countries between 2007 and 2011/12. The largest increases occurred in the countries hit the hardest by the crisis: Spain (over 7 points, the highest), Ireland (over 5 points), and Greece (5 points). On average, across the OECD countries, the drop in income was twice as large for the bottom $10 \%$ of the population, the poorest, compared with the top $10 \%$, the wealthiest.

Macroeconomic variables such as per capita income levels, unemployment rates or fuel prices have an important influence on transport demand (Cordera et al., 2015). Many academic studies of the effects of the global economic crisis provide evidence that some changes in transport behaviour originated during the recessionary phases (Rothengatter, 2011; Sobrino and Monzón, 2014; Campos-Soria et al., 2015). In Australia, where the impact of the crisis was much lower than in other countries, the baby boomers switched to more environmentally friendly travel modes at the beginning of the financial crisis (Kamruzzaman et al., 2014). In Reykjavik, during the first months of the crisis, people modified their travel behaviour by reducing their trip frequencies and car use, using public transport more, and working more at home (Ulfarsson et al., 2015). As far as transport is concerned, residents of central areas were less sensitive to the crisis than residents of the suburbs, and less affected by the reduction in the number of trips. The relations between urban form, location and travel distances have been studied in the case of the Danish region of Zealand/Copenhagen by comparing changes in travel behaviour between 2006/07 and 2010/11 (Nielsen, 2015). The analysis shows that travel distance was reduced, residents preferring nearby destinations as part of cost reducing strategies. Travel was thus more "rational" or less "wasteful" and urban form and location seem essential factors for changing travel behaviour. Adopting a qualitative approach, the RUPTURES research project (Arcadis et al., 2012) studied the impacts on transport in France, where the effects of the crisis were felt later and less severely than in Spain. The findings highlighted the contradictory effects that could affect daily mobility. Despite a trend for mobility to decrease and optimization of transport modes, individuals could also be compelled to undertake longer trips, to access jobs for instance. The results also showed the wide variety of solutions that could be implemented by individuals. Recently, Alonso et al. (2017) analysed the effects of urban sprawl and the financial crisis on public transport (PT) performance in six Spanish metropolitan areas between 2007 and 2012. Evidence was made of a drop in PT trips and a systematic loss of PT efficiency in all areas despite the implementation of different PT supply strategies.

Other research projects have studied changes in travel behaviour due to different factors, but not specifically in the context of the financial and economic crisis. However they shed light on the short-term adaptation strategies of individuals and households with regard to transport. For example, Yang and Timmermans (2013) show for the Netherlands that increasing fuel price decreases travel time expenditure by car. The impact is greater for compulsory travel on weekdays and leisure travel time at weekends, and the reduction in car travel time is made up for by time spent in other transport modes. In the metropolitan area of Brisbane, analysis of the effects of location on transport costs (public transport fares and car fuel) show that these increase as one moves away from the centre (Li et al., 2015). In outer suburban areas, use of less fuel-efficient vehicles and high public transport fares increase transport costs. Transport 
disadvantage and vulnerability are therefore greater for the poorest households living in these areas.

To analyse the effects of the economic crisis on household transport expenditure we have selected the case of Spain, because it is one of the European countries most affected by the crisis (Pueyo and Hernández, 2013). A drop in macroeconomic indicators has occurred since 2008. First, Spain's GDP peaked in 2008 at $€ 1.12$ billion and it fell to a minimum of $€ 1.03$ billion in 2013, but started to rise again in 2014 (National Accounts of Spain - INE). Second, the impact of the crisis on employment in the Spanish economy was devastating (CarballoCruz, 2011). Even though the unemployment rate in Spain was already fairly high during the period of growth (8.3\% in 2007), according to the Labour Force Survey (INE, Encuesta de Población Activa), 3.6 million jobs were destroyed in Spain from 2007 to 2013. The construction sector was the most affected by the crisis, with the number of jobs falling by $55 \%$ between 2008 and 2013 due to the bursting of the housing bubble. The collapse of the construction sector increased unemployment at an unprecedented rate until 2013, reaching its highest level of $26.9 \%$. It decreased slightly in 2014 (24.4\%), in line with the growth in GDP mentioned above. Moreover, public services and the welfare system were severely impacted due to the contracting economy and the ensuing reduction in the tax take (Pueyo and Hernández, 2013). Between 2007 and 2011 the crisis affected the entire Spanish population, but especially the poorest: the average income of the poorest $10 \%$ of the population fell $12.9 \%$, whereas the average income of the richest $10 \%$ fell $1.4 \%$ (OECD, 2014). In this period, Spain became the country in the European Union with the largest economic inequality.

Together with the reduction in the Spanish economic activity, there were changes in transportrelated indicators. Since the beginning of the crisis, both the price of fuel and public transport fares have increased to a very similar extent (Cascajo et al., 2014). With regard to the automobile market, while the number of new car registrations remained stable since 2004, it collapsed between 2008 and 2012, when it started to recover. Yet, in 2014, the number of new car registrations was half that in 2007. The motorization rate has remained more or less stable in this period, with the highest level in 2007, $486 \mathrm{veh} / 1,000$ inhab., and $471 \mathrm{veh} / 1,000$ inhab. in 2013 (Sobrino and Monzón, 2014; Dirección General de Tráfico). With respect to transport demand indicators, both the use of urban public transport and the vehicular traffic peaked in 2007, then decreased until 2013 (11.1\% and 14.1\%, respectively) and recovered slightly in 2014 (Ministerio de Fomento, 2014).

In this paper the impacts of the macroeconomic crisis in the case of Spain are studied under two different angles: the household expenditure patterns and the strategies implemented by public transport authorities. With regard to household expenditure patterns, three questions are investigated: What trade-offs have households made between the different expenditure items? What are the main constituents of household transport expenditure? Are there any differences between households according to their purchasing power or their residential location? With regard to public transport provision, the objective is to investigate what measures have transport authorities implemented in a context of decreasing public resources and transport demand.

The paper is organised as follows. Section 2 describes data and methodological issues. Section 3 analyses the major expenditure items for Spanish households and then considers transport expenditure. Section 4 presents the strategies implemented by public transport (PT) authorities during the crisis to cope with changes in transport demand and budget restrictions. The last section discusses major findings and draws policy-oriented conclusions, which insist on the importance of sustainable transport policies and the interactions between transport and land use. 


\section{Methodology}

The approach is based on both quantitative and qualitative information. The quantitative investigation is implemented to perform an analysis of household transport expenditure at national level (Section 2.1). Given that in Spain, the competences in urban and metropolitan public transport are assigned to the public transport authorities, we then shift to the local level in a qualitative approach. It is based on in-depth interviews with public transport policy makers in six metropolitan areas (MA) for which we analyse what kind of measures were applied to mitigate the negative impacts of the crisis (Section 2.2). It provides important insights in terms of policy recommendations for public transport systems affected by an economic crisis.

\subsection{Quantitative analysis: data source}

The quantitative investigation was an analysis of the Spanish household's expenditure on transport. We undertook specific processing of data from the Household Budget Survey (EPF, Encuesta de Presupuestos Familiares). This survey has been carried out every year since 2006 with a yearly sample of more than 20,000 households (INE, n.d.). The micro data is available via open access on the INE's internet site. The data presented here cover the 9-year period 20062014.

The EPF provides comprehensive details of the overall expenditure of Spanish households through 4 nested nomenclatures. Division 07 covers transport expenditure. It contains a breakdown of all the expenditure related to passenger transport: purchase of vehicles (including cars, vans, motorcycles and scooters, bicycles), operation of personal transport (spares, accessories, repairs and servicing, fuel and motor oils, parking, tolls) and transport services (fares of rail and road transport, air transport, maritime transport, season tickets). For the purpose of this paper, we also included in the transport expenditures "Transport-related Insurance", initially included in the Division 12 ("Miscellaneous goods and services"). In the same way, "Housing-related Insurance" was integrated within housing expenditure (Division 04).

Our analysis of household budgets using the EPF focused on the social and the spatial effects of the crisis. The social effects were studied through household purchasing power, which is measured in per capita expenditure quintiles. The first quintile (Q1) contains the poorest $20 \%$ of households while the last (Q5) the wealthiest $20 \%$ of households. The micro data of the EPF do not provide precise spatial information. In particular, it is not possible to identify the residents of metropolitan areas. Thus, for assessing spatial effects, we used a less accurate indicator, the class of population density of the area of residential location (high-, medium- and low-density), which is directly available in the data base. The density classes are those used by Eurostat and the European national statistical agencies (Eurostat, 2003):

- high-density areas, at least 500 inhabitants $/ \mathrm{km}^{2}$;

- medium-density areas, between 100 and 499 inhabitants $/ \mathrm{km}^{2}$;

- low-density areas, fewer than 100 inhabitants $/ \mathrm{km}^{2}$.

We have used two indicators, both at the overall level (the Spanish households as a whole) and at the quintile (or residential location) level. The variation in expenditures, measured in absolute value or through a base index of 100 in 2007 (the last year before the beginning of the crisis), shows how households have adapted their behaviours to their changing resources. The share of total expenditure that is devoted to transport shows whether it becomes a lower or a higher priority for households than other items. The time series, which were obtained either directly from INE Base or by processing the EPF data, are expressed in constant Euros (2006 Euros), unless otherwise specified. The statistical analyses were conducted using the software R. 
Regardless of the indicator analysed, we systemically calculated the $95 \%$ confidence intervals. These confidence intervals are featured in the figures of section 3 in light grey.

\subsection{Qualitative approach: in-depth interviews with PT authorities and operators}

In addition to the quantitative analysis, we also performed a qualitative research through indepth semi-structured interviews. The information was collected for the CIME research project (Ray et al., 2015) in six metropolitan areas.

Among the existing qualitative techniques, the in-depth interview is an established and accepted qualitative social research method (Patton, 2002; Legard et al., 2003) which is increasingly used in transport research to provide additional comprehension elements (Hine, 1996; Hine and Scott, 2000; Beirão and Cabral, 2007; Tseng et al., 2009; Hrelja, 2015). We followed the general process for conducting in-depth interviews: plan, develop instruments, collect data, analyse data, and disseminate findings (Boyce and Neale, 2006). We first identified the stakeholders to be interviewed and then developed an interview guide with the questions or issues to be explored during the interview, according to three fields:

- Has the mobility changed as a result of the crisis? What other factors may have influenced mobility in your Municipality/Region?

- What transport policy measures have been undertaken in your region/municipality in response to the crisis?

- What specific actions concerning public transport supply have been implemented: actions to counter the crisis (e.g. investments, social fares), actions to reduce costs and actions to optimize transport services?

The interviewees consisted of high-level personnel employed by the PT authorities and the main transport operators. In view of the limited number of people interviewed, two per MA, the list of transport policy measures was complemented by access to official documents and a press review. However, the list stated in this article is neither exhaustive nor official but it gives a first categorization and some examples of transport policy measures in a time of crisis that we have not found in literature except for D'Acierno et al. (2014) who focused on public transport network optimization.

The selected MA to identify the transport policy measures are Madrid, Barcelona, Valencia, Seville, Vitoria and Pamplona (Fig. 1). The first four are among Spain's six most populated cities. They have differing economic levels and unemployment rates.

Table 1 sets out information on demographic and spatial size and PT travel demand for the selected MA. Four MA present in 2014 moderate levels of PT use, with less than 100 annual PT trips per inhabitant, while Madrid and Barcelona show the highest rates, around 200 trips per inhabitant. The reduction in the travel demand between 2007 and 2014 is observed in all areas except for Vitoria, where a strong sustainable mobility plan was designed before the beginning of the crisis and implemented during the crisis period. 


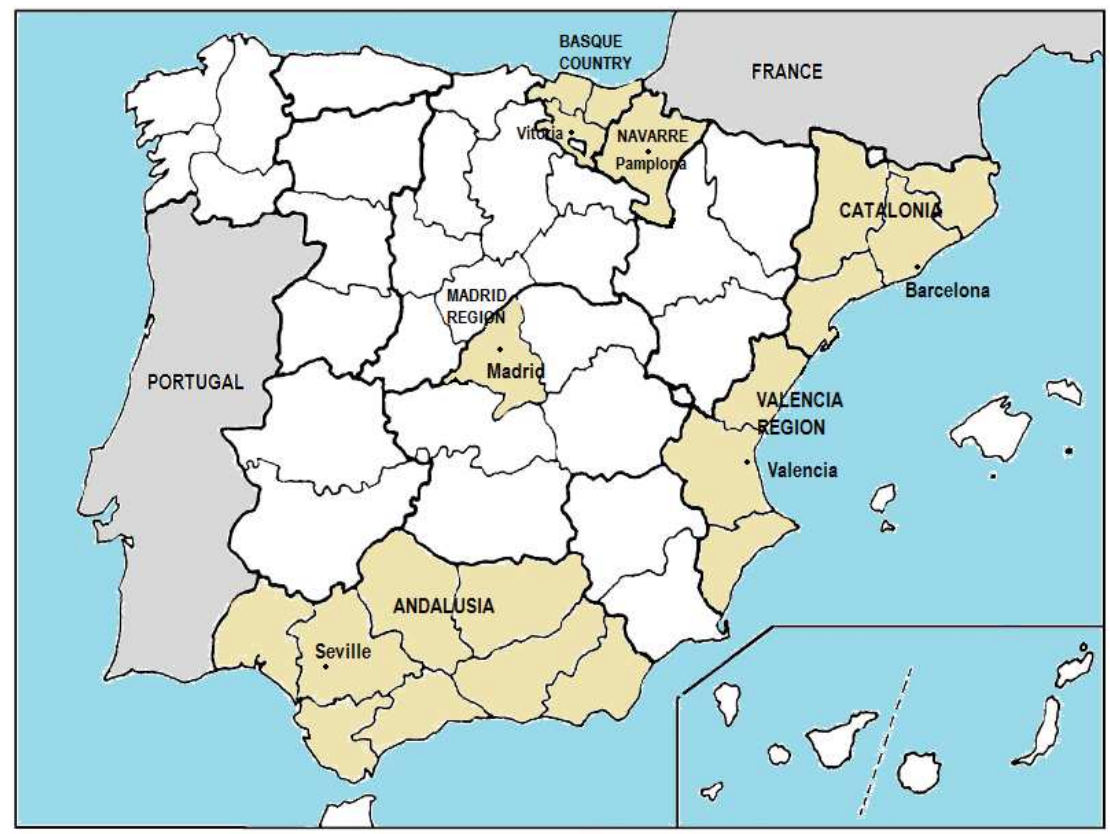

Fig. 1. Location of the six selected metropolitan areas for in-depth interviews with public transport authorities.

Table 1. Characteristics of the selected metropolitan areas in 2014.

\begin{tabular}{lrrrrr}
\hline \multirow{2}{*}{ Metropolitan Areas } & \multirow{2}{*}{$\begin{array}{c}\text { Population } \\
\mathbf{2 0 1 4}\end{array}$} & \multirow{2}{*}{$\begin{array}{c}\text { Surface } \\
\text { (inhabitants) }\end{array}$} & \multicolumn{2}{c}{$\begin{array}{c}\text { Annual PT } \\
\text { trips in 2014 }\end{array}$} & \multicolumn{2}{c}{$\begin{array}{c}\text { Variation (\%) of annual PT } \\
\text { trips per inhabitant }\end{array}$} \\
\cline { 6 - 7 } & $6,454,440$ & 8,030 & 219.6 & $-1,1$ & $-20,5$ \\
\hline Madrid & $5,026,709$ & 3,239 & 182.1 & 7,8 & $-5,4$ \\
\hline Barcelona & $1,910,206$ & 1,415 & 91.4 & 1,4 & $-17,7$ \\
\hline Valencia & $1,480,793$ & 4,221 & 75.3 & $-9,4$ & $-12,0$ \\
\hline Seville & 337,989 & 92 & 96.7 & 10,0 & $-22,1$ \\
\hline Pamplona & 242,082 & 277 & 78.1 & 0,5 & 60,4 \\
\hline Vitoria & & & & & \\
\hline
\end{tabular}

Source: INE and Monzón et al., 2016.

\section{Transport expenditure in the Spanish household budget in 2006-2014}

The crisis and high rates of unemployment have severely influenced the spending patterns of Spanish households. Three approaches are applied in this section to present changes in spending: overall household expenditure (3.1), total transport expenditure (3.2), and structure of the transport expenditure (3.3). The amounts spent are indicated in constant Euros (2006) unless otherwise specified.

\subsection{Household budget: a tightening of belts}

The average household budget, which increased continuously during the first half of the decade, fell in constant Euros from 2008 onwards and in current Euros from 2009 (Fig. 2). The decrease continued until 2013 and slowed down notably in 2014 in current Euros and even increased slightly in constant Euros ${ }^{1}$, but it is still too early to know if the recovery will last. Family budgets decreased by $2.2 \%$ per year in current Euros and $3.7 \%$ per year in constant Euros in 2007-2014. In 2014, the average household budget was only $85 \%$ of that in 2007 , in current

\footnotetext{
${ }^{1}$ Increase not significant at the $5 \%$ threshold.
} 
Euros, and $77 \%$ in constant Euros. The crisis reduced the disparity between average family budgets according to residential location. In 2007, the average household budget was around $€ 32,000$ in high- and medium-density areas and $€ 27,000$ in low-density areas, while in 2014 the range of the average values was between $€ 24,600$ (high density areas) and $€ 22,000$ (lowdensity areas).

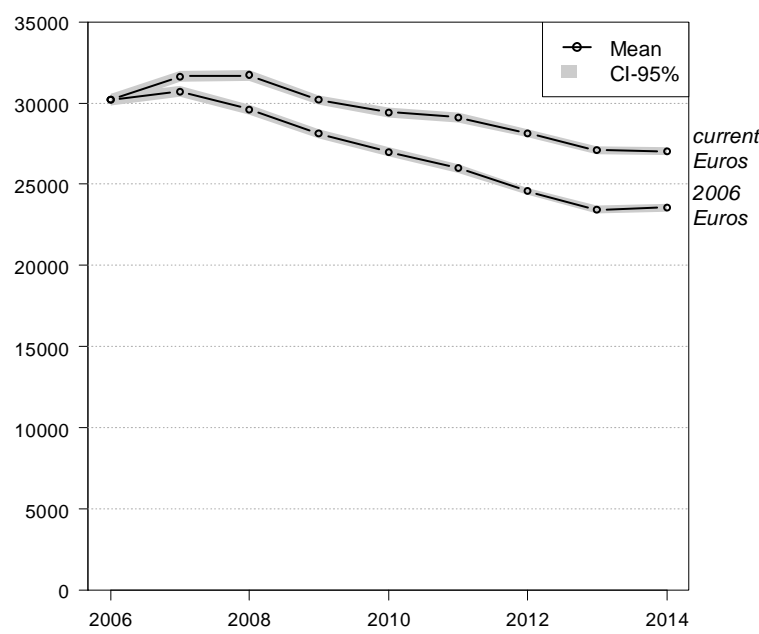

Fig. 2. Average household expenditure in 2006-2014 (current and $2006 €$ ).

Source: EPF data, calculations by authors.

Housing, the main item in the household budget, increased during 2006-2011 and then decreased slightly during the next three years (Fig. 3). Given that total spending diminished, the share of housing skyrocketed from a quarter of the average household budget in 2007 to a third in 2014. It reached its highest level in 2009 in high-density areas, where housing difficulties are more acute, and in 2011 in the other areas. In the low-density areas, the housing budget then remained stable and thus the amount in 2014 was higher than in 2007. Conversely, in the other areas, spending on housing diminished and returned in 2014 to a level that is comparable to 2007.

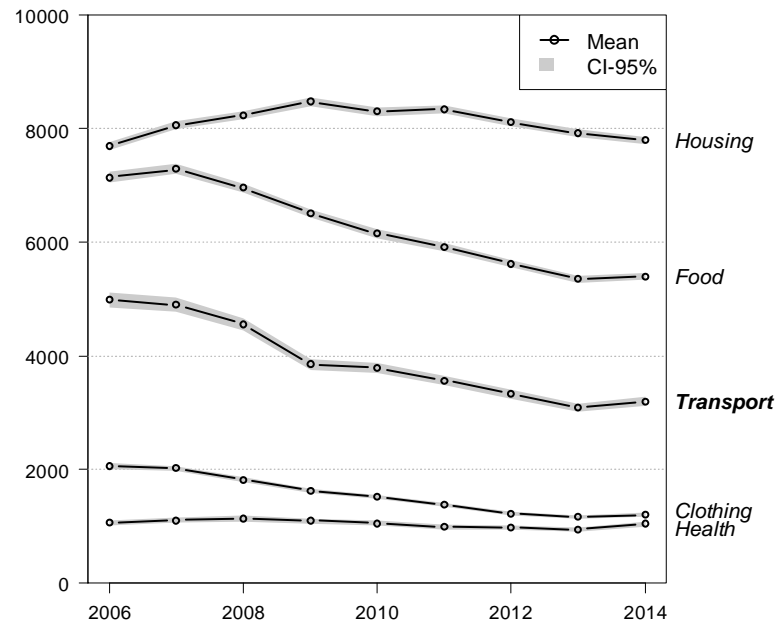

Fig. 3. Average household expenditure on the main expenditure items in 2006-2014 (2006€).

Source: EPF data, calculations by authors.

To withstand the simultaneous increase in housing expenses and the first impacts of the crisis, households reduced the amounts they spent on other items such as food, transport and clothing 
from 2008 onwards. The downward trend did not slow down until 2014 and the decrease over the entire period was significant. In constant Euros, the amounts spent on food, transport and clothing in 2014 were respectively 74\%, 65\% and 59\% of what they had been in 2007, while the figure for housing was $97 \%$. Spending on health was maintained at roughly the same level (€1,103 in 2007 and $€ 1,043$ in 2014).

\subsection{Transport expenditure: an absolute and a relative decline}

Of the main expenditure items, transport was one of the most affected by the crisis. The average amount spent on transport reached its lowest level in 2013 (slightly under $€ 3,100$ ), which was $63 \%$ of the amount spent in 2007 . The fact that transport expenditure declined faster than that on other budget items meant that it accounted for a smaller proportion of average household expenditure: it fell from $15.9 \%$ in 2007 to $13.6 \%$ in 2014, and even $13.2 \%$ in $2013^{2}$.

Transport expenditure is very sensitive to the economic position of the household and two phenomena can be observed (Fig. 4). As one moves from Q5 (the 20\% richest households) to Q1 (the $20 \%$ poorest households), the decrease became not only smaller, but also appeared later. As a consequence, transport expenditure was halved between 2007 and 2013 for the richest quintile and remained fairly constant for the poorest. The relative level of transport expenditure and the way it has changed also varied according to the economic position of households (Fig. 5). Whatever the year, the wealthiest devoted a higher proportion of their expenditure to transport than the poorest quintile. In 2007-2014, the ratio rose in the case of the poorest households, with a peak in 2013. The share remained quite stable for the households from the 2nd quintile and declined for the others: -1.2 points for the 3rd quintile, -2.5 points for the 4 th and -4 points for the 5 th. This shows that it is harder for the poorest quintile to reduce its transport costs than for the other quintiles.

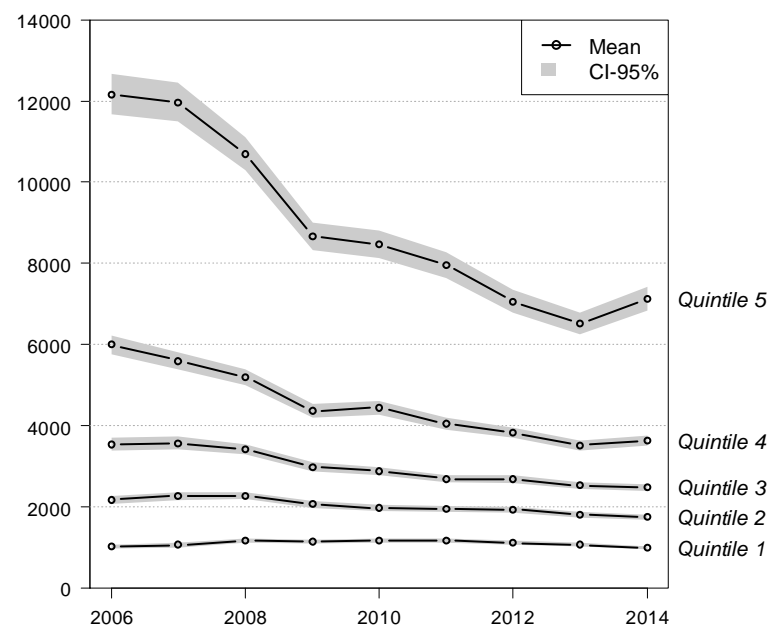

Fig. 4. Average household expenditure on transport in 2006-2014 according to quintile (2006 €)

Source: EPF data, calculations by authors.

\footnotetext{
${ }^{2}$ However, the decrease seems to have begun before the beginning of the crisis because the share fell from $16.5 \%$ to $15.9 \%$ between 2006 and 2007.
} 


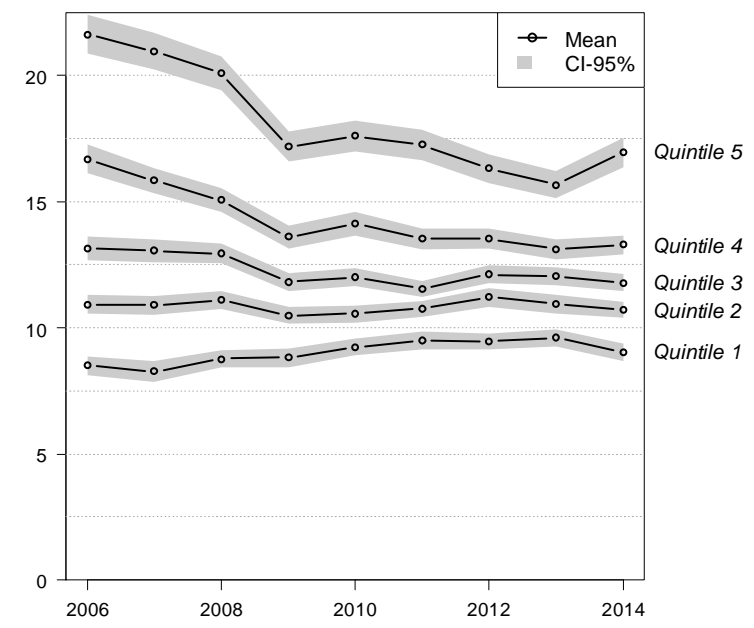

Fig. 5. Percentage of transport in household expenditure in 2006-2014 according to quintile.

Source: EPF data, calculations by authors.

The level of transport expenditure is weakly linked to residential location but the effect is more noticeable for the share of transport (Tables 2 and 3). The more densely populated areas present the lowest percentage of the household budget that is devoted to transport ${ }^{3}$. In all three types of areas, a significant drop was observed in 2009 with the lowest percentage in 2013. In 20072014, the fall was 2 percentage points in the low- and high-density areas and 3 in the mediumdensity areas.

Table 2. Average transport expenditure in 2006-2014, according to population density of residential location $(2006 €)$

\begin{tabular}{|l|c|c|c|c|c|c|c|c|c|}
\hline Density & $\mathbf{2 0 0 6}$ & $\mathbf{2 0 0 7}$ & $\mathbf{2 0 0 8}$ & $\mathbf{2 0 0 9}$ & $\mathbf{2 0 1 0}$ & $\mathbf{2 0 1 1}$ & $\mathbf{2 0 1 2}$ & $\mathbf{2 0 1 3}$ & $\mathbf{2 0 1 4}$ \\
\hline High & 4,874 & 4,876 & 4,683 & 4,011 & 3,995 & 3,724 & 3,599 & 3,464 & 3,538 \\
$(\mathbf{9 5 \%}$ CI) & $(4,676-$ & $(4,682-$ & $(4,505-$ & $(3,874-$ & $(3,864-$ & $(3,590-$ & $(3,479-$ & $(3,346-$ & $(3,406-$ \\
& $5,073)$ & $5,069)$ & $4,861)$ & $4,149)$ & $4,126)$ & $3,858)$ & $3,718)$ & $3,582)$ & $3,670)$ \\
\hline Medium & 5,593 & 5,642 & 5,288 & 4,382 & 4,496 & 4,326 & 4,195 & 3,705 & 3,765 \\
$(\mathbf{9 5 \%}$ CI) & $(5,315-$ & $(5,368-$ & $(5,055-$ & $(4,191-$ & $(4,282-$ & $(4,128-$ & $(3,994-$ & $(3,550-$ & $(3,597-$ \\
& $5,870)$ & $5,916)$ & $5,522)$ & $4,574)$ & $4,711)$ & $4,524)$ & $4,396)$ & $3,859)$ & $3,932)$ \\
\hline Low & 4,691 & 4,874 & 4,913 & 4,159 & 4,088 & 4,264 & 3,887 & 3,682 & 3,845 \\
$(\mathbf{9 5 \%}$ CI) & $(4,450-$ & $(4,636-$ & $(4,696-$ & $(3,963-$ & $(3,911-$ & $(4,088-$ & $(3,739-$ & $(3,539-$ & $(3,694-$ \\
& $4,932)$ & $5,112)$ & $5,129)$ & $4,355)$ & $4,264)$ & $4,439)$ & $4,035)$ & $3,826)$ & $3,997)$ \\
\hline
\end{tabular}

Source: EPF data, calculations by authors.

Table 3. Percentage of household expenditure spent on transport in 2006-2014, according to population density of residential location

\begin{tabular}{|l|c|c|c|c|c|c|c|c|c|}
\hline Density & $\mathbf{2 0 0 6}$ & $\mathbf{2 0 0 7}$ & $\mathbf{2 0 0 8}$ & $\mathbf{2 0 0 9}$ & $\mathbf{2 0 1 0}$ & $\mathbf{2 0 1 1}$ & $\mathbf{2 0 1 2}$ & $\mathbf{2 0 1 3}$ & $\mathbf{2 0 1 4}$ \\
\hline High & 15.3 & 14.7 & 14.1 & 12.6 & 12.9 & 12.3 & 12.3 & 12.2 & 12.5 \\
$(\mathbf{9 5 \%}$ CI) & $(14.8-15.8)$ & $(14.2-15.2)$ & $(13.7-14.5)$ & $(12.3-13.0)$ & $(12.6-13.3)$ & $(12.0-12.7)$ & $(12.0-12.6)$ & $(11.9-12.5)$ & $(12.2-12.9)$ \\
\hline $\begin{array}{l}\text { Medium } \\
(\mathbf{9 5 \%} \text { CI) }\end{array}$ & 18.0 & 17.4 & 16.7 & 14.6 & 15.3 & 14.7 & 14.9 & 13.9 & 14.3 \\
$(17.4-18.7)$ & $(16.7-18.1)$ & $(16.1-17.2)$ & $(14.0-15.1)$ & $(14.7-15.8)$ & $(14.2-15.2)$ & $(14.3-15.4)$ & $(13.5-14.4)$ & $(13.7-14.8)$ \\
\hline $\begin{array}{l}\text { Low } \\
(\mathbf{9 5 \%} \text { CI) }\end{array}$ & 17.9 & 17.5 & 17.2 & 15.4 & 15.4 & 16.0 & 15.1 & 14.8 & 15.2 \\
$(17.2-18.6)$ & $(16.8-18.2)$ & $(16.6-17.8)$ & $(14.8-16.0)$ & $(14.9-15.9)$ & $(15.5-16.5)$ & $(14.7-15.6)$ & $(14.4-15.3)$ & $(14.8-15.7)$ \\
\hline
\end{tabular}

Source: EPF data, calculations by authors.

Transport expenditure has dropped markedly during the crisis, but it is nevertheless still the third highest item of expenditure. The change in the proportion of expenditure devoted to

\footnotetext{
${ }^{3}$ The $95 \%$ confidence intervals never overlap between, on the one side, low or medium density areas and on the other side, high density areas. It is not the case between medium and low density areas.
} 
transport appears to be related to the residential location and the purchasing power of the household.

\subsection{Structure of transport expenditure: new cars in the hot seat}

Transport expenditure is made up of the purchase cost of personal vehicles and the costs of transport use (operating costs for personal vehicles and fares for urban and inter-city public transport $)^{4}$. These items showed very different patterns of change (Fig. 6).

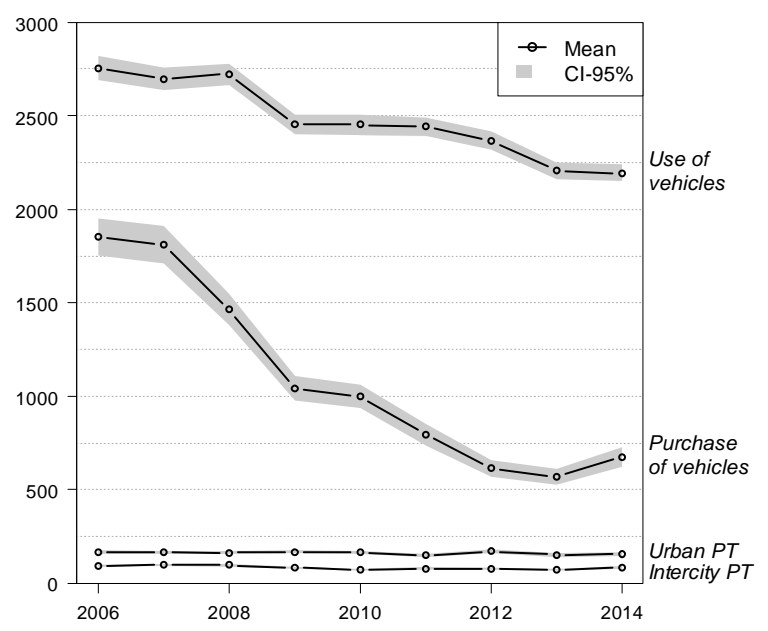

Fig. 6. Average household expenditure on transport per item in 2006-2014 (2006€).

Source: EPF data, calculations by authors.

The annual amount spent on vehicle purchase decreased much quicker than transport use: it fell $63 \%$, from $€ 1,800$ in 2007 to $€ 680$ in 2014 . The fall is mainly due to the purchase of new cars for which the decrease was significant from the very beginning of the crisis (-22\%) (Fig. 7). Despite the fact that the incentive schemes to maintain the sales of new vehicles $\left(2000 \mathrm{E}^{5}\right.$ and PIVE $^{6}$ ) definitely helped either to stop the decline (2010) or to slow it down slightly (2013), in 2013 households spent the lowest amount on new cars, a quarter of the amount they spent in 2007. However, in 2014, in the context of a slight increase in total household expenditure (in constant Euros), this percentage increased to $34 \%$ of the amount in 2007, while the figures for second-hand cars and motorcycles were $48 \%$ and $29 \%$ respectively. Counter to these trends, purchase of bicycles has risen ( $+28 \%$ between 2007 and 2014), but the expenditure involved is still very small (on average $€ 15$ per household in 2014).

The amounts allocated to vehicle purchase and the way they have changed are very similar in the three categories of urban density. However, the differences between the quintiles are important and the level of spending on vehicle purchase is hierarchical. In 2014, the most affluent $20 \%$ of households spent three times the total amount spent by the other $80 \%$ of households on vehicle purchase. While the amounts spent on vehicle purchase fell in all the quintiles, the collapse of the purchase of new cars, shown in Fig. 7, was essentially due to the households in the $4^{\text {th }}$ and, above all, the $5^{\text {th }}$ quintile. A household of the $5^{\text {th }}$ quintile devoted on average $€ 5,100$ to the purchase of new cars in 2007 but only $€ 1,430$ in 2013 . It is also the

\footnotetext{
${ }^{4}$ These analyses do not consider expenditure on sea and air transport which accounted for between $2 \%$ and $3 \%$ of household expenditure over the reporting period.

${ }^{5}$ Plan 2000E: national scheme of direct aid for the purchase of cars between 2009 and 2010.

${ }^{6}$ Plan PIVE: national program of incentives for efficient vehicles between 2012 and 2013.
} 
wealthiest households who drove the change in trend visible in 2014 as their spending on new cars rose to $€ 1,930$.

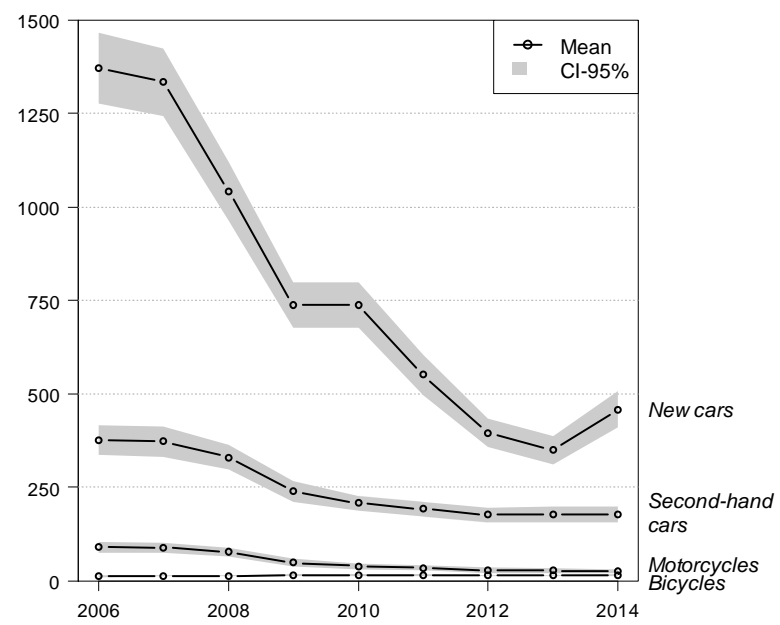

Fig. 7. Average household expenditure on vehicle purchase according to vehicle type in 2006-2014 $(2006 €)$.

Source: EPF data, calculations by authors.

Spending on transport use fell from $€ 2,960$ in 2007 to $€ 2,433$ in 2014 , i.e. by nearly $20 \%$. About $90 \%$ of this amount was for personal vehicles, $6 \%$ for urban PT and the rest for inter-city PT, without any substantial changes in their relative importance in 2006-2014. Expenditure on all these items has declined since 2007, slightly and erratically in the case of urban public transport (Fig. 8). The use of passenger cars declined in a more regular manner than the two other items (Fig. 9). The decrease in spending in a context of a rise in unitary prices of fuel and public transport fares (Cascajo et al., 2014) indicates a greater fall in the amounts consumed. Table 4 shows that the amount of fuel bought annually by each household has shrunk by one quarter since 2007.

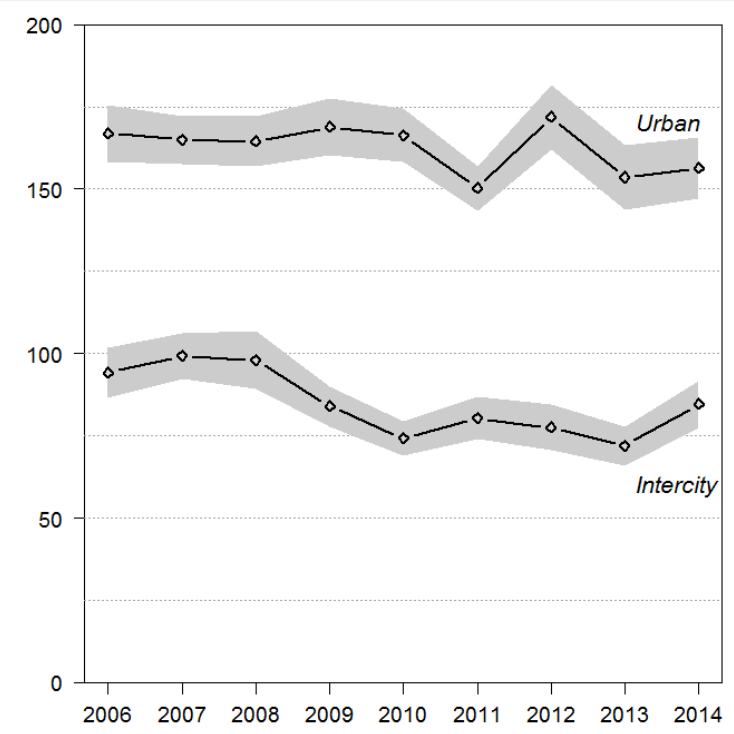

Fig. 8. Average household expenditure in the use of public transport modes for all households $(2006 €)$.

Source: EPF data, calculations by authors. 


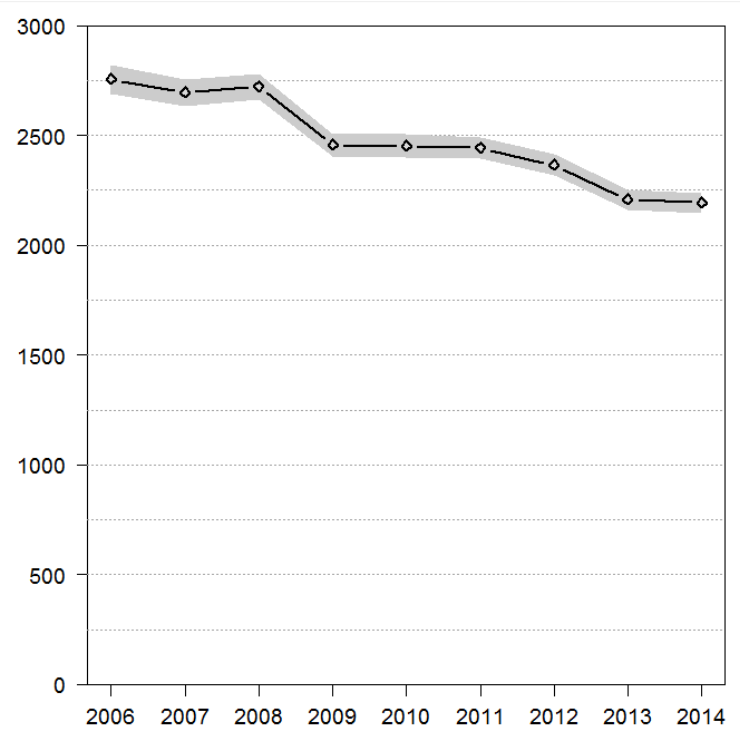

Fig. 9. Average household expenditure in the use of private transport modes for all households (2006€).

Source: EPF data, calculations by authors.

Table 4. Household fuel and lubricant consumption in litres, in 2006-2014 (base 100 in 2007)

\begin{tabular}{|l|c|c|c|c|c|c|c|c|c|}
\hline & $\mathbf{2 0 0 6}$ & $\mathbf{2 0 0 7}$ & $\mathbf{2 0 0 8}$ & $\mathbf{2 0 0 9}$ & $\mathbf{2 0 1 0}$ & $\mathbf{2 0 1 1}$ & $\mathbf{2 0 1 2}$ & $\mathbf{2 0 1 3}$ & $\mathbf{2 0 1 4}$ \\
\hline Volume & 92.3 & 100.0 & 98.0 & 93.7 & 88.5 & 83.6 & 77.1 & 73.4 & 72.9 \\
\hline (95\% CI) & $(90.3-94.3)$ & $(98.1-101.9)$ & $(96.0-100.0)$ & $(92.0-95.5)$ & $(86.7-90.3)$ & $(82.0-85.2)$ & $(75.5-78.7)$ & $(71.9-74.8)$ & $(71.5-74.4)$ \\
\hline
\end{tabular}

Source: EPF data, calculations by authors.

The overall decline did not apply to households in the $1^{\text {st }}$ quintile. Until 2012 , their spending on personal vehicles remained fairly steady, while their spending on urban PT increased (from $€ 69$ in 2007 to $€ 96$ in 2012). In contrast, during the next two years, while their total budget continued to decline, their spending on the use of the different modes of transport exhibited a downward trend (a 10\% fall in 2 years). The differences due to residential location were less marked. However, the drop in spending was the smallest in the low-density areas because of the relative stability in the amounts spent on operating cars: a 9\% drop between 2007 and 2014 (compared to a drop of $22 \%$ and $25 \%$ respectively in high- and medium-density areas).

Households thus reacted promptly, in the very first year, to the onset of the crisis by considerably reducing their purchases of new cars, without turning towards second-hand cars or motorcycles (the growth in spending on bicycles has been inconsequential). Spending on vehicle purchase then continued to be gradually cut further, but without any real reduction in motorization rates (Cascajo et al., 2014). Spending on transport use was also affected by the crisis, but less significantly. These overall effects must be however qualified according to the type of household: those whose resources (monetary resources or modal opportunities) are the lowest have fewer adaptation alternatives and are also the least able to reduce their transport costs. This echoes previous findings (Arcadis et al., 2012; Li et al., 2015). 


\section{Strategies implemented by the Public Transport Authorities}

After having exposed how the crisis has changed patterns of household transport expenditure, this section analyses how PT authorities and operators reacted to the crisis. It brings together the main measures taken by six MA authorities (Madrid, Barcelona, Valencia, Seville, Pamplona, and Vitoria).

D'Acierno et al. (2014) and Veenman et al. (2015) point out that the literature contains very few examples of austerity measures in the transport sector during the crisis. Measures that are mentioned in the literature and official documents were used as a starting point for the discussion with the interviewees from PT authorities and operators. Although they mentioned some new items during the interviews, the results cannot be considered as a comprehensive list of austerity measures. A systematic survey with a larger panel of cities would be necessary to assess the importance (according to the number of cities concerned) and impact of each of the stated measures on cost-reduction and network efficiency.

Transport authorities reacted to the crisis in two somewhat contradictory ways. A first set of actions aimed at increasing the number of passengers again. Because there was no improvement in travel demand, then they introduced on the one hand, austerity measures to reduce costs and on the other hand, measures to increase revenues which aimed to partially offset the public budget cuts. Well-organised and powerful public authorities were able to identify coherent strategies, taking the opportunity presented by the crisis to find new resources (including advertising) and optimize transport networks. Some cities which had well-defined long-term strategies even benefited from economic stimulus plans to implement the infrastructure investments needed for network development. However, many recovery plan budgets were spent on conventional maintenance (reconstruction of sidewalks for instance) with no impact on crisis-resilience or the quality of the transport network.

The strategies of the public authorities have focused on service reductions (leading to a deterioration in the quality of services for users), fare increases, and other types of optimization that have no impact on transport provision. Table 5 shows the different types of actions taken in the surveyed cities. 
Table 5. Classification of measures taken during the crisis by the Spanish metropolitan areas selected.

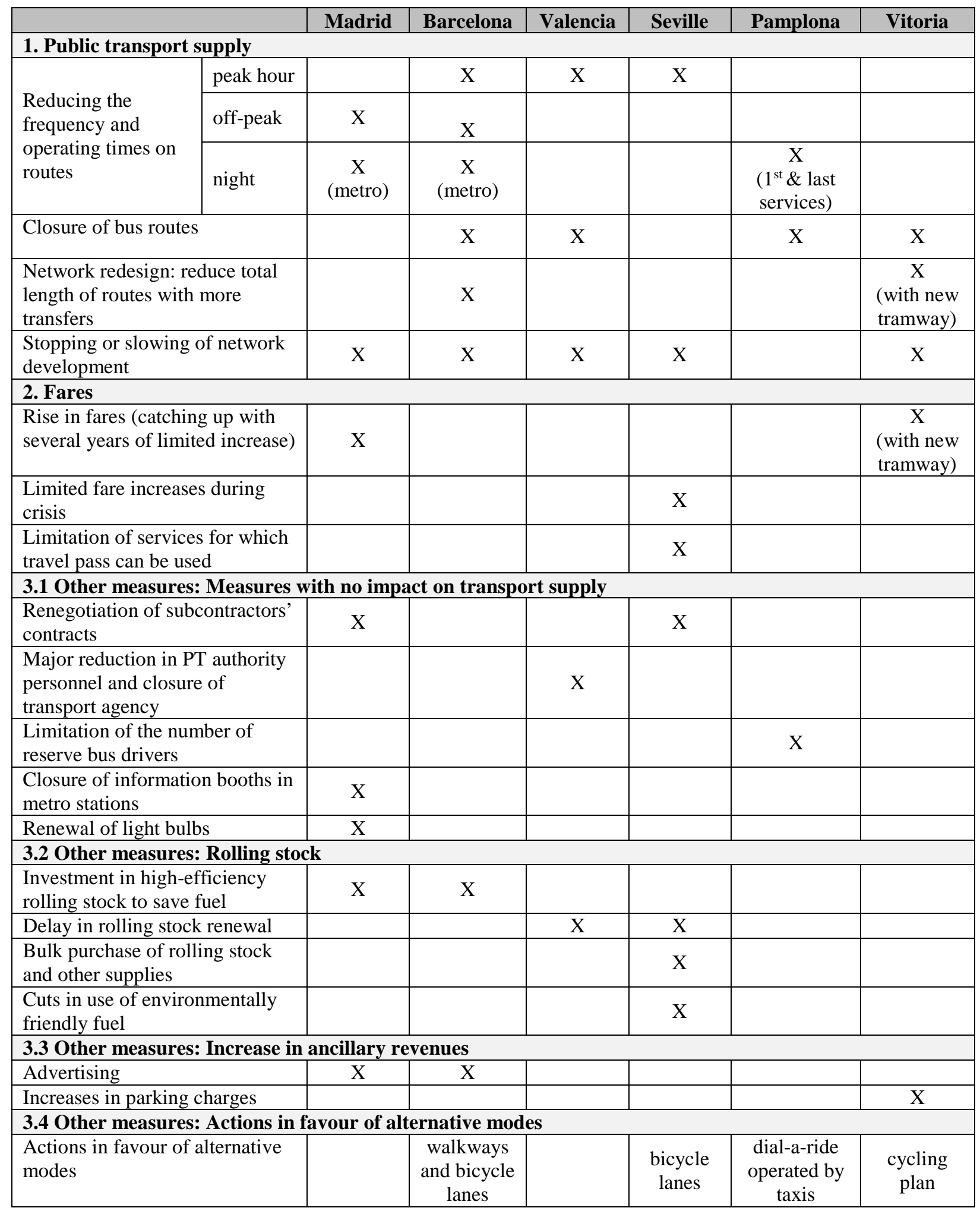

Source: Interviews with public transport authorities and operators; Ray et al., 2015; Castillo-Manzano et al., 2015; Marqués et al., 2015. 


\subsection{Measures concerning public transport supply}

Many of the measures implemented by the transport authorities attempted to make immediate cuts in transport supply by reducing levels of service and/or reorganizing the bus network. These types of measures have been categorized by D'Acierno et al. (2014).

Many networks preferred to reduce the frequency of bus services rather than to close a bus route completely. Madrid has mainly reduced off-peak services. Barcelona refused to carry out peakhour reductions, except for some intercity buses, but made considerable reductions to off-peak services, especially for routes servicing industrial zones. Seville reduced bus frequencies, eradicating more than half the increases in services that had taken place on the network since 2001. Pamplona cut some low-traffic routes, replacing them by on-demand services operated by taxis. Moreover, the city reduced the number of buses and reserve drivers at night and during weekends, with possible impacts on reliability.

Reducing operating hours is one of the most frequently observed measures for decreasing operating costs. The Metro in Barcelona, which used to run 24 hours a day, now closes at midnight on Monday to Thursday; the Madrid metro closes at midnight on Sunday to Thursday, compared with 1:30 before the crisis. Similarly, the city of Pamplona has reconsidered the viability of the first and last services on each bus route on the basis of their occupancy.

Vitoria and Barcelona have optimized their bus networks by replacing their traditional routes with a new orthogonal grid scheme ${ }^{7}$, keeping similar trip times but requiring more transfers. This model was successfully implemented in the city of Vitoria in 2009. Implementation began in Barcelona in October 2012: it is being carried out gradually and the network has not yet been finalized. Operating costs have consequently been reduced by some $10 \%$. These measures show a desire to rationalize the allocation of resources in order to achieve a better cost/benefit ratio.

Measures involving transport supply in the medium or long term were also taken. Almost all the surveyed cities had to stop or suspend their network expansion plans:

- Madrid stopped the construction of the suburban railway line to the town of Navalcarnero $30 \mathrm{~km}$ away;

- Barcelona suspended extensions of metro lines 5, 9 and 10;

- Seville suspended work on metro lines 2, 3 and 4;

- Vitoria had to abandon the expansion of its bike-share network due to financing problems and slowed down the construction of its tramway because of the crisis.

\subsection{Fares}

The cities generally increased their fares in line with inflation. In Seville, the public authority chose not to apply fare increases in the critical crisis years. Such action to limit the pressure on users has a cost. Indeed, the public service delegation contracts guarantee operators fare increases each year. Public authorities have to make up for the loss of income if they do not apply the terms of the contract. The difficulty of applying measures in the case of large longterm concession contracts is also stated in Veenman et al. (2015). In Vitoria, however, a fare increase coincided with the commissioning of the tramway lines which constitute a marked improvement in the transport supply. In other cases, fares were increased indirectly, by reducing the services previously included in the price of the season ticket, as in Seville.

\footnotetext{
${ }^{7}$ The orthogonal network is basically a square bus network substituting direct connections by trips with a transfer between routes. The consequence is a significant reduction in the total length of bus routes (and thus a decrease in operating costs) but with more transfers, which implies penalties for users in terms of inconvenience and time.
} 
Some networks offer social fares. These are generally subsidised by social services and are not always integrated within transport policy. But in times of crisis some social services have also had to make budget cuts and remove subsidies. In Valencia, the "youth" subsidy, funded by social services for young persons was abolished in 2011. However, it was reintroduced in 2014. Social measures are still particularly advantageous on some networks, as in Barcelona where a quarterly subscription provides an $80 \%$ fare reduction for the unemployed.

\subsection{Other measures}

The stimulus policy and the quest for long-term cost savings have sometimes accelerated the replacement of rolling stock with more efficient models, or attempted to achieve economies of scale by making bulk purchases for several urban networks (buses, other supplies), as in Andalusia. To achieve cost reductions in the short and medium terms, the Madrid metro replaced standard light bulbs with LEDs in order to make energy savings of up to $75 \%$ and reduced the ancillary services provided to users by closing 25 reception rooms.

Conversely, some networks have increased their ancillary revenues. In particular, Madrid has made use of advertising. Some metro lines are sponsored and take on the name of the sponsoring brand, as is the case with Vodafone, the mobile and internet operator: travellers now talk about "Vodafone line 2" or "Vodafone Sol" station. The network also plans to provide sites for the stores of sponsors like Carrefour, a major retail chain.

One major problem, not listed in the table, was caused by the cut in the planning budget. Some cities delayed their regular mobility surveys (Madrid, Seville, Navarre among them) meaning they had less data to take informed decisions. The same happened with the budget for consultancy studies that could have helped them understand how to improve the efficiency of PT services.

Most of the mentioned measures were directly linked to the crisis, but some were introduced for other reasons. Cities like Barcelona and Vitoria pursued the strategy they had outlined in their sustainable mobility plans despite the crisis. The city of Vitoria, for example, significantly increased parking charges in its city-centre in 2009 in the middle of the crisis. This measure, which was part of the plan for sustainable mobility in the city and made it possible to increase ancillary revenues, has enhanced the overall coherence and success of the restructuring of the public transport system (the construction of the new tramway and the rationalization of bus routes) and the actions in favour of cycling. Beyond specific transport measures, Barcelona lays the emphasis on transport links and urban planning, and encourages the empowerment of secondary centres in its first and second suburban rings to limit the need to travel to the heart of the city, thus reducing transport costs in a time of crisis. The motivation behind such measures is mainly environmental.

\section{Discussion and conclusions}

Most analyses of the crisis impacts focus on data covering a short time span. National and local public institutions in charge of data collection and processing are also sensitive to the economic context and have to cope with substantial cuts in public finance. This is the case, for example, for mobility surveys, whose production has slowed down markedly in nearly all Spanish cities (Monzón et al., 2008; Monzón et al., 2013; Monzón et al., 2016; Centro de Estudios Ambientales, 2015). In this paper, we have analysed changes on household transport budgets over a 9 year period (2006-2014), which covers the end of economic growth and the economic crisis. 
The Spanish economy was growing rapidly at an annual rate of $1.4 \%$ until 2007 and then shrank by $1.1 \%$ per year up to 2013 . The impact of the crisis on urban mobility resulted in a net reduction of over $10 \%$ in both car mileages and PT trips. The latter is somewhat unexpected and probably due to reductions in both the demand side and the supply side: reduction of commuting needs because of the high rates of unemployment and reduction of services (number of routes, frequencies, etc.) implemented by transport authorities to reduce costs. Part of the fall of car mileages could be linked to the peak travel phenomenon, e.g. Spanish youth licensing rates increased modestly between 1999 and 2009 (Sivak and Shoettle, 2012) and household motorisation rates remained stable during the crisis even though new car registrations plummeted. Research on peak travel has shown evidence that the driving factors of car use are of different types, they interact in a complex way, and the influence of economic factors has changed (Goodwin and Van Dender, 2013). Future complementary analysis in terms of peak travel, which need long-time travel data bases, could shed additional light on changes on car use during the crisis.

The intensity and duration of the Spanish economic crisis give rich insights into the trade-offs households made between income reduction and transport expenditure, and the adaptation strategies that public authorities adopted to manage mobility. Families had to face two interconnected problems: an increase in the number of unemployed members and a reduction in available household budgets for their expenses. Our findings show that transport was one of the most affected items in the household budget and the amounts allocated to transport are highly dependent on car use and purchase. According to the aggregate trends observed in the results, we can interpret that households made two kinds of economic decisions: not to buy new vehicles (sales have dropped by 63\% between 2007 and 2014), and to reduce the use of transport, particularly cars, as much as possible (expenditure has fallen by $18 \%$ ). However, the situation differs considerably according to their economic position. The households in the poorest quintile were unable to reduce their transport expenses possibly because their budgets were already tight and were dedicated mainly to public transport, which suffered from the higher fares. The transport expenditure of poor households rose from $8.3 \%$ of their total expenditure (2007) to $9.6 \%$ (2013). The effect of the crisis was exactly the opposite for the wealthiest quintile: their expenditure dropped from $21 \%$ of their total expenditure (2007) to $15.7 \%$ (2013). This could mean that the wealthy have more options to adapt to the crisis since they can delay the purchase of a new car and it is likely that they can also make fewer noncommuting trips and, more generally, modify their mobility patterns.

There are also differences in adaptation according to the density of the residential area. The results give some insights on the difficulty that residents of low density areas may have to change their mobility behaviour, as this group reduced their expenditure by only $9 \%$, whereas those in medium or high density areas saved up to $25 \%$. This suggests that the inhabitants of Spanish low density districts are more car dependent, having few or no alternatives to car use for their daily trips, similarly to the "forced car ownership" in the Melbourne suburban areas (Currie et al., 2009) and the car as "essential in order to maintain a reasonable minimum standard of living" in English rural areas (Smith et al., 2012).

The reduction in public budgets together with that of public transport demand have forced public transport authorities to implement a variety of measures to reduce operating costs and make transport systems more efficient. The study of the six metropolitan areas reveal a variety of actions to cope with the reduction of subsidies. Some of them did not influence transport provision and set out to provide some extra incomes: new advertising campaigns, renting public spaces for commercial activities in metro and bus stations, cross-subsidies between parking and public transport, etc. However, most decisions aimed at reducing public transport supply (closing some low demand routes, reducing service frequencies and operating hours) to 
decrease operating costs, and increasing fare prices in order to increase the operator's farebox revenue.

Some Spanish cities have been able to improve the performance of their network, maintaining trip times but with more transfers. Others, whose budget's fragile equilibrium was quickly destroyed by the crisis, had to reduce transport supply systematically, with no time for planning. The primary objective was to improve in the short term the economic efficiency leaving aside in many cases effectiveness considerations of the local public transport systems (Karlaftis and Tsambulas, 2012). All areas, except Vitoria, have shown a loss of PT efficiency (Alonso et al., 2017). For further research, a detailed assessment of the usefulness of these measures on the economic health of PT operators and their impact on transport demand would be necessary. Future research should also evaluate if specific groups of population have been more negatively impacted than others; for example, the reduction of levels of service may have affected more the residents of the suburbs and the off-peak travellers than the residents of central areas and the peak-hour commuters. Analysis of disaggregated data on daily travel (i.e. household travel surveys) and in-depth interviews of households on their room for manoeuvre and adaptation strategies would shed additional light on these questions.

Our analysis shows that the adaptation is easier for the wealthiest public transport networks (but this applies also to households as seen above) allowing all parties take more resilient decisions. Some of the measures that were applied because of the crisis were intended to improve efficiency. They could therefore be appropriate even under normal conditions, in the absence of a crisis (Alonso et al., 2015). These measures generally target sustainability and the environment by reducing transport intensity and car dependency and by promoting public transport and bicycle use. Well-designed policies could achieve synergies resulting in more sustainable modal splits, as in the case of Barcelona, Vitoria and Valencia, where the part of motorised private vehicles has decreased. Other actions could include a greater use of information and communication technology that may enhance access to services and mobility and improve the quality of public transport services (Grieco, 2015; Morfoulaki et al., 2015). These actions should be further supported by a coherent long-term land-use policy aimed at limiting the urbanising areas (González Pérez, 2007) and increasing functional mixing and the density of economic activities and residences.

Despite the limitations of this study, it provides evidence that may help stakeholders in the difficult exercise of finding ways to address the impacts of an economic crisis on mobility. In the medium and long term, reducing car dependency helps to reduce overall costs for public authorities and households. However, this is only possible when the quality and density of PT supply are really high (Preston and Rajé, 2007) and when clear measures are taken to control urban sprawl (EEA, 2006) and achieve mixed land-use. If efficient public transport systems can be achieved in wealthy periods, they will be more resilient in periods of recession.

\section{Acknowledgements}

The content of this paper is partially based on the findings of the research project CIME (The Crisis and its Impacts on Mobility in Spain. Measure, analysis and benchmarking for the French case), funded by the R\&D French Transport Programme PREDIT. 


\section{References}

Alonso, A., Monzón, A., Cascajo, R., 2015. Comparative analysis of passenger transport sustainability in European cities. Ecological Indicators, 48, 578-592.

Alonso, A., Monzón, A., Cascajo, R., 2017. Measuring Negative Synergies of Urban Sprawl and Economic Crisis over Public Transport Efficiency: The Case of Spain. International Regional Science Review, DOI : 10.1177/0160017616687361 (First Published January 24, 2017).

Arcadis, TRANSAE, LET, 2012. Ruptures. Impact d'une Crise Économique Majeure sur les Comportements de Mobilité Résidentielle et Transport des Ménages. Rapport Final de Recherche, PREDIT G06 Politiques de transport, 132 p.

Beirão, G., Cabral, J. S., 2007. Understanding attitudes towards public transport and private car: A qualitative study. Transport Policy, 14 (6), 478-489.

Boyce, C., Neale, P., 2006. A Guide for Designing and Conducting In-Depth Interviews for Evaluation Input. Pathfinder International Tool Series, Monitoring and Evaluation.

Campos-Soria, J. A., Inchausti-Sintes, F., Eugenio-Martin, J. L., 2015. Understanding tourists' economizing strategies during the global economic crisis. Tourism Management, 48, 164-173.

Carballo-Cruz, F., 2011. Causes and consequences of the Spanish economic crisis: Why the recovery is taken so long? Panoeconomicus, 3, 309-328.

Cascajo, R., Diaz Olvera, L., Monfort, V., Monzón, A., Plat, D., Ray, J-B., 2014. Situation de crise et mobilité quotidienne. Le cas de l'Espagne. 51ème Colloque ASRDLF. 7-9 juillet 2014, Marne-la-Vallée (France).

Castillo-Manzano, J. I., López-Valpuesta, L., Marchena-Gómez, M., 2015. Seville: A city with two souls. Cities, 42, 142-151.

Centro de Estudios Ambientales, Ayuntamiento de Vitoria-Gasteiz, 2015. Análisis de los resultados de la encuesta de movilidad 2014 de Vitoria-Gasteiz. http://blogs.vitoriagasteiz.org/medios/files/2015/01/an\%C3\%A1lisis-encuesta-movilidad-2014.pdf

Cordera, R., Canales, C., dell'Olio, L., Ibeas, A., 2015. Public transport demand elasticities during the recessionary phases of economic cycles. Transport Policy, 42, 173-179.

Currie, G., Richardson, T., Smyth, P., Vella-Brodrick, D., Hine, J., Lucas, K., Stanley, J., Morris, J., Kinnear, R., Stanley, J., 2009. Investigating links between transport disadvantage, social exclusion and well-being in Melbourne - Preliminary results. Transport Policy, 16, 97105.

D’Acierno, L., Gallo, M., Biggiero, L., Montella, B., 2014. Replanning public transport services in the case of budget reductions. WIT Transaction on the Built Environment, 138, 77-88.

Dhameja, N., 2010. Financial Crisis: Impact, Challenges and Way Out. Indian Journal of Industrial Relations, 45 (3): 11-16.

EEA (European Environment Agency), 2006. Urban sprawl in Europe - The ignored challenge. Copenhagen. http://www.eea.europa.eu/publications/eea_report_2006_10

Eurostat, 2003. Household Budget Surveys in the EU: Methodology and recommendations for harmonisation. Luxembourg: Eurostat http://epp.eurostat.cec.eu.int/portal/page?_pageid=1073,1135281,1073_1135295\&_dad=porta $1 \&$ schema=PORTAL\&p_product_code=KS-BF-03-003 
Gerstberger, C., Yaneva, D., 2013. Analysis of EU-27 household final consumption expenditure - Baltic countries and Greece still suffering most from the economic and financial crisis. Eurostat, Statistics in Focus, 2/2013, 8 p.

http://ec.europa.eu/eurostat/documents/3433488/5585636/KS-SF-13-002-EN.PDF/a4a1ed61bac7-4361-a3f0-4252140e1751?version=1.0

González Perez, J. M., 2007. Urban Planning System in Contemporary Spain. European Planning Studies, 15 (1), 29-50.

Goodwin, P., Van Dender, K., 2013. 'Peak Car' - Themes and Issues. Transport Reviews, 33 (3), 243-254.

Grieco, M., 2015. Poverty mapping and sustainable transport: A neglected dimension. Research in Transportation Economics, 51, 3-9.

Hine, J., 1996. Pedestrian travel experiences: Assessing the impact of traffic on behaviour and perceptions of safety using an in-depth interview technique. Journal of Transport Geography, 4 (3), 179-199.

Hine, J., Scott, J., 2000. Seamless, accessible travel: Users' views of the public transport journey and interchange. Transport Policy, 7, 217-226.

Hrelja, R., 2015. Integrating transport and land-use planning? How steering cultures in local authorities affect implementation of integrated public transport and land-use planning. Transportation Research Part A: Policy and Practice, 74, 1-13.

INE, n.d. Encuesta de Presupuestos Familiares. Metodologia. 95 p.

http://www.ine.es/metodologia/t25/t2530p458.pdf

Kamruzzaman, M., Yigitcanlar, T., Washington, S., Currie, G., Turrell, G., 2014. Australian baby boomers switched to more environment friendly modes of transport during the global financial crisis. International Journal of Environmental Science and Technology, 11 (8), 21332144.

Karlaftis, M. G., Tsamboulas, D., 2012. Efficiency measurement in public transport: Are findings specification sensitive? Transport Research Part A - Policy and Practice, 46 (2), 392402.

Legard, R., Keegan, J., Ward, K., 2003. In-depth Interviews. In Ritchie, J., Lewis, J. (Eds.), Qualitative research practice: a guide for social science students and researchers. Sage Publications, Thousand Oaks, California.

Li, T., Dodson, J., Sipe, N., 2015. Differentiating metropolitan transport disadvantage by mode: Household expenditure on private vehicle fuel and public transport fares in Brisbane, Australia. Journal of Transport Geography, 49, 16-25.

Marqués, R., Hernández-Herrador, V., Calvo-Salazar, M., García-Cebrián, J. A., 2015. How infrastructure can promote cycling in cities: Lessons from Seville. Research in Transportation Economics, 53, 31-44.

Ministerio de Fomento, 2014. Anuario Estadístico. Dirección General de Programación Económica. Subdirección General de Estadísticas y Estudios.

Monzón, A., Cascajo, R., Alonso, A., 2013. Informe 2011 del Observatorio de la Movilidad Metropolitana. Ministerio de Agricultura, Alimentación y Medio Ambiente. http://www.observatoriomovilidad.es/images/stories/05_informes/Informe_OMM2011.pdf 
Monzón, A., Cascajo, R., Barberán, A., Díaz, M. L., 2016. Informe 2014 del Observatorio de la Movilidad Metropolitana. Madrid. Ministerio de Agricultura, Alimentación y Medio Ambiente. http://www.observatoriomovilidad.es/en/publications/reports.html

Monzón, A., Cascajo, R., Jordá, P., Pérez, P., Rojo, I., 2008. Informe 2006 del Observatorio de la Movilidad Metropolitana. Ministerio de Medio Ambiente y Medio Rural y Marino, y Ministerio de Fomento.

Morfoulaki, M., Myrovali, G., Kotoula, K., 2015. Increasing the attractiveness of public transport by investing in soft ICT based measures: Going from words to actions under an austerity backdrop - Thessaloniki's case, Greece. Research in Transportation Economics, 51, 40-48.

Nielsen, T. A. S., 2015. Changes in transport behaviour during the financial crisis. An analysis of urban form, location and transport behaviour in the greater Copenhagen area 2006-2011. Research in Transportation Economics, 51, 10-19.

OECD, 2014. Rising Inequality: Youth and Poor Fall Further Behind - Income Inequality Update - June 2014. Paris: OECD. http://www.oecd.org/social/OECD2014-Income-InequalityUpdate.pdf

Patton, M. Q., 2002. Qualitative research and evaluation methods (3rd ed), Sage, Thousand Oaks, California.

Preston, J., Rajé, F., 2007. Accessibility, mobility and transport-related social exclusion. Journal of Transport Geography, 15 (3), 151-160.

Pueyo Campos, Á., Hernández Navarro, M. L., 2013. España ante la Gran Recesión del siglo XXI. M@ppemonde 111; Dossier: España. http://mappemonde.mgm.fr/num39/index.html

Ray, J. B., Monfort Salvador, V., Monzon, A., Cascajo, R., Plat, D., Diaz Olvera, L., 2015. CIME. La Crise et ses Impacts sur la Mobilité en Espagne. Mesures, analyses et enseignements pour le cas français. Rapport final PREDIT-ADEME. Villeurbanne: ARCADIS, $87 \mathrm{p}$. http://www.movicite.com/activite-de-recherche/projet-cime

Rothengatter, W., 2011. Economic crisis and consequences for the transport sector. In: Rothengatter, W., Hayashi, Y., Schade, W. (Eds.), Transport Moving to Climate Intelligence. New Chances for Controlling Climate Impacts of Transport after the Economic Crisis. New York: Springer, 9-28.

Sivak, M., Schoettle, B., 2012. Recent Changes in the Age Composition of Drivers in 15 Countries. Traffic Injury Prevention, 13, 126-132.

Smith, N., Hirsch, D., Davies, A., 2012. Accessibility and capability: the minimum transport needs and costs of rural households. Journal of Transport Geography, 21, 93-101.

Sobrino, N., Monzón, A., 2014. The impact of the economic crisis and policy actions on GHG emissions from road transport in Spain. Energy Policy, 74, 486-498.

Terazi, E., Senel, S., 2011. The effects of the global financial crisis on the Central and Eastern European Union Countries. International Journal of Business and Social Science, 2 (17), 186192. http://ijbssnet.com/journals/Vol_2_No_17/25.pdf

Tseng, Y. Y., Verhoef, E., de Jong, G., Kouwenhoven, M., van der Hoorn, T., 2009. A pilot study into the perception of unreliability of travel times using in-depth interviews. Journal of Choice Modelling, 2 (1), 8-28. 
Ulfarsson, G. F., Steinbrenner, A., Valsson, T., Kim, S., 2015. Urban household travel behaviour in a time of economic crisis: Changes in trip making and transit importance. Journal of Transport Geography, 49, 68-75.

Veenman, W., Augustan, K., Enoch, M., Faivre d'Arcier, B., Malpezzi, S., Wijmenga, N., 2015. Austerity in public transport in Europe: the influence of governance. Research in Transportation Economics, 51, 31-39.

Yang, D., Timmermans, H., 2013. Analysis of influence of fuel price on individual activitytravel time expenditure. Transport Policy, 30, 40-55.

Websites:

Ayuntamiento de Vitoria-Gasteiz. http://www.vitoria-gasteiz.org/we001/was/

we001Action.do?idioma=es\&aplicacion=wb021\&tabla=contenido\&uid=_5e2b2877_120d224 e518_ $7 \mathrm{fe} 7$

Diari Oficial de la Comunitat Valenciana, Decreto Ley 7/2012. http://www.docv.gva.es/portal/ficha_disposicion.jsp?id=24\&sig=009545/2012\&L=1\&url_list $\underline{\mathrm{a}=}$

Dirección General de Tráfico, http://www.dgt.es/es/seguridad-vial/estadisticas-e-indicadores

Instituto Nacional de Estadística, Cuentas económicas, Contabilidad nacional de España. http://www.ine.es/jaxi/menu.do?type=pcaxis\&path=\%2Ft35\%2Fp008\&file $=$ inebase $\& \mathrm{~L}=0$

Instituto Nacional de Estadística, Encuesta de Población Activa. http://www.ine.es/dyngs/INEbase/es/operacion.htm?c=Estadistica_C\&cid=1254736176918\& $\underline{\text { menu}=\text { ultiDatos\&idp }=1254735976595}$

Instituto Nacional de Estadística, Encuesta de Presupuestos Familiares, micro-datos 2006-2014. http://www.ine.es/dyngs/INEbase/es/operacion.htm?c=Estadistica_C\&cid=1254736176806\& $\underline{\text { menu }=\text { resultados \&secc }=1254736195147 \& i d p=1254735976608}$

Observatorio de la Movilidad Metropolitana (OMM), Informes 2006-2014. http://www.observatoriomovilidad.es/

Press articles:

http://www.lasprovincias.es/horta-morvedre/201410/12/xirivella-elimina-todos-semaforos$\underline{20141012000518 \text {-v.html }}$

http://www.elperiodico.cat/ca/noticias/barcelona/bus-vao-dos-sentits-dobla-volum-transit$\underline{3595568}$

http://ccaa.elpais.com/ccaa/2012/08/21/madrid/1345554056_203588.html

http://ccaa.elpais.com/ccaa/2012/08/21/madrid/1345564226_315551.html

http://www.larazon.es/detalle_hemeroteca/noticias/LA_RAZON_482274/4583-el-abonomensual-zona-a-subira-90-centimos-y-el-metrobus-20-centimos\#.Ttt1PqgaV2xxjqq

http://www.lavanguardia.com/local/barcelona/20141015/54417169428/ronda-litoralbarcelona-convertirse-paseo.html

http://elpais.com/diario/1994/11/04/economia/783903608_850215.html

http://www.larazon.es/detalle_hemeroteca/noticias/LA_RAZON_406265/6005-lamanifestacion-nacional-por-la-escuela-publica-recorre-madrid\#.Ttt1KUWAANUFmwy 
http://www.eldiario.es/politica/PSOE-renovado-autocritica-defendiendoZapatero_0_195630940.html

http://elpais.com/diario/2010/05/13/espana/1273701601_850215.html

http://ccaa.elpais.com/ccaa/2012/05/25/valencia/1337976812_407574.html

http://ccaa.elpais.com/ccaa/2012/11/22/valencia/1353588707_716138.html 